\title{
NMR and Microorganisms
}

\section{Jean-Philippe Grivet*}

Centre de Biophysique Moléculaire CNRS, Université d'Orléans, Rue Charles Sadron, F-45071 Orléans Cedex 2, France

\begin{abstract}
This article is an introduction to the use of NMR for the investigation of microbial physiology and metabolism. NMR parameters which determine the sensitivity and resolving power of the method are reviewed. A broad survey of current applications follows. Qualitative uses are described first; they include compound identification and localisation. Quantitative aspects, such as $\mathrm{pH}$, concentration and flux measurements are then examined, as well as the corresponding experimental constraints. The review ends with suggestions of possible future developments in instrument capabilities aimed at improving sensitivity: higher fields, spectroscopic and imaging microprobes.
\end{abstract}

\section{Introduction}

The first report on the application of NMR to microorganisms is that of Eakin et al. on the yeast, Candida utilis (1). During the past 27 years, many developments have taken place, which make in vivo NMR a very useful tool in the study of microbial physiology and metabolism. It is the purpose of this introductory review to provide the reader with an orientation to the field. It is comprised of four parts. We first list a few characteristics of the NMR technique which are deemed important for metabolic investigation. We then describe several applications of NMR, first as a qualitative tool then as a quantitative instrument. We have taken the liberty to mention advances which have taken place in related fields, such as biofluid analysis and NMR studies of mammalian cells or whole organs, whenever they were perceived as useful and readily adaptable to the case of micro-organisms. We end by mentioning various probable or desirable future developments.

\section{Some Aspects of NMR of Importance in Microbiology}

We assume that the reader has some knowledge of NMR. We will be mainly concerned with small molecules, observed either in homogenous solutions (supernatant or growth medium, cell extracts) or inside living cells.

\section{Sensitivity}

The sensitivity of the NMR experiment should probably be the foremost concern of prospective users. It depends on the following factors.

1) Nature of the nucleus: Each magnetic nucleus is characterised by a spin quantum number I $>0$ and $\mathrm{a}$ gyromagnetic ratio $\gamma$. Several elements which play an important role in biochemistry have "low $\gamma$ " nuclei ( $\mathrm{Mg}, \mathrm{Ca}$ ) and present special problems. A further point is that nuclei with $\mathrm{I} \geq 1$ (such as ${ }^{14} \mathrm{~N}$ ) have a quadrupole moment and display very broad lines when bound in a molecule. Exceptions include alkali, alkaline earth, and chlorine ions, provided they are not bound to a carrier macromolecule.

2) Operating magnetic field: The sensitivity depends roughly on the square of the static field. As the price of a spectrometer is also a steep function of the magnetic field, there is an obvious economic limitation here. It is compounded with the requirement of a wide sample access, because magnet prices also increase with sample bore.

3) Active volume: Provided the sample has a correct shape and is relatively homogenous, sensitivity is roughly proportional to the volume inside the radio-frequency coil. Thus, at constant concentration, a $20 \mathrm{~mm}$ tube should yield a signal about four times as intense as a $10 \mathrm{~mm}$ one.

4) Concentration of resonant nuclei: This is the main limiting factor but it depends on many variables, such as the effective concentration of the compound of interest and the relative abundance of the isotope being studied. Many elements have an abundant isotope devoid of magnetic moment while the magnetically active isotope is rare. Such is the case, to varying degrees, for $\mathrm{C}, \mathrm{O}, \mathrm{Ca}$ and $\mathrm{S}$, and also for $\mathrm{N}$ because the main isotope is very difficult to use in metabolic studies, due to its broad signal. Enriched compounds are expensive and the range of available substances is limited. The case of hydrogen is almost the opposite; here, the intense solvent resonance tends to swamp the informative signals, and special pulse sequences must be used (2).

5) Line-width: The physics of NMR shows that the previous parameters determine the area of each signal. Therefore, the broader the signal, the smaller its amplitude and the more likely that it vanishes amidst noise and baseline artefacts. When working with supernatants or cell extracts, the contributions to the line-widths are those found for all solution work: solids suspended in the medium, paramagnetic impurities, viscous solution; they can all be partly or totally removed. In the case of living cells, the line-width is likely to be dominated by the sample's own heterogeneity. Some causes, such as gas bubbles, can be controlled.

6) Accumulation time: The signal to noise ratio increases as the square root of the number of scans accumulated. This result is exact insofar as the sample remains intact (cells remain viable, do not settle, gas bubbles are not formed). Further, the necessary number of scans puts a lower limit on the time resolution of each experiment. It may happen that a decent sensitivity cannot be reached because of limited instrument time and relaxation problems (see next paragraph).

7) Relaxation delay: Sensitivity depends on the spin lattice relaxation time $\mathrm{T} 1$, the pulse flip angle and the pulse repetition time. A relaxation delay is usually inserted before 
each excitation pulse. For quantitative work, a delay of at least $3 \mathrm{~T}_{1}$ is required if the experimental signal is to be within $10 \%$ of the true signal. Shorter delays can be used, along with correction factors. A pair of spectra, recorded with respectively short and very long delays, are used to compute correction factors. This procedure relies on the assumption that relevant parameters do not evolve in time. For solution work, relaxation reagents can be added. They serve two useful purposes: decreasing $T_{1}$ and suppressing the Overhauser effect (next paragraph).

8) Decoupling: The spectra of nuclei other than hydrogen are usually recorded under complete proton decoupling. Since different nuclei may interact differently with surrounding protons, proton irradiation complicates the recording of quantitative spectra: one must resort to gated irradiation wherein the decoupling effect is retained, but the differential Overhauser enhancement is suppressed. Conditions for quantitative recording have been given $(3,4)$. It is worth noting that the radio-frequency field used for decoupling is attenuated by ionic solutions, an effect which becomes important for large sample volumes and high frequencies. The higher the proton resonance frequency, the larger the spectral width required of the decoupler. One may either use higher decoupler power (at the risk of overheating the sample) or sophisticated decoupling schemes $(5,6)$.

Inverse detection, where heteronuclear resonances are detected via proton signals, is making significant inroads in the field of in vivo NMR: it promises important gains in sensitivity and somewhat better resolution (7). The theoretical sensitivity advantage of inverse compared to straight forward detection of nucleus $X$ is $\left(\gamma_{H} / \gamma_{X}\right)^{3}$. This large factor may not be fully realised because most reverse probes only accept $5 \mathrm{~mm}$ sample tubes and because of the deleterious effect of the intense and broad water signal. The method is also ineffective when applied to nuclei weakly coupled to protons, such as carboxylic carbons. Lastly, quantitation is difficult.

Implicitly, we have been considering the sensitivity required to detect a signal. It is usual to assume that a signal to noise ratio of at least 3 is necessary for detection. Better performance is required for quantification by use of line integrals. It has been shown (8) that the precision of any integral is numerically equal to the inverse of the signal to noise ratio; a signal which is ten times the noise will be integrated to a precision of $10 \%$.

We have left aside the complicated problem of NMR visibility. It sometimes happens that a compound, abundant enough to be detected inside cells, is not seen (or seen with low sensitivity) on the experimental spectrum. A common explanation is that these small molecules are bound to large carrier macromolecules, with very slow motions. The corresponding signals are therefore broadened beyond recognition. A discussion is best left to specific cases.

\section{Resolution}

In the early applications of NMR to microbial physiology and metabolism, spectral resolution was rarely an issue. The ranges of ${ }^{13} \mathrm{C}$ and ${ }^{15} \mathrm{~N}$ chemical shifts is such that few spectral overlaps were observed. Phosphorus spectra are somewhat crowded, for instance in the phosphomonoester region. This favourable state of affairs is changing because more complex systems are being investigated and also because proton NMR, which has a smaller frequency dispersion, is being used more often. In some cases higher operating fields will alleviate the problem, but the almost definitive solution is two- or multi-dimensional NMR , using multiple labelling and one- or multi-dimensional acquisition and processing. An example is provided by the recent investigation of glyphosate metabolism by Hutton et al. (9). Proton NMR investigations have also benefited from 2-D (COSY) techniques; see for instance the review by Navon (10) on proton-phosphorus 2D techniques.

\section{Other Instrumental Requirements}

Most experiments useful in metabolic NMR can be done using a typical high resolution spectrometer, provided it has multi-nuclear and reverse detection capabilities. Pulsed field gradients are becoming increasingly useful. They are used to shorten pulse sequences but also to weigh NMR signals according to the diffusion coefficients of the relevant molecules. Aspin echo sequence is applied in the presence of a pair of pulsed gradients. The final signal intensity is a function of the diffusion coefficient of the compound under study. Thus, diffusion ordered two-dimensional spectroscopy is fast becoming a powerful analytical technique for complex mixtures (11). As already mentioned, a wide bore and ample spectrometer time are definite advantages.

Modern high resolution NMR puts stringent requirements on the stability of the magnetic field, of the spectrometer electronics and of the sample temperature. Because of the broader line-widths and simpler pulse sequences used, metabolic NMR is less demanding. For in vivo experiments, it is often possible to dispense with the field/frequency lock.

Solid state NMR and micro-imaging are two other important techniques. They both require wide-bore magnets, specific probes and special electronics.

\section{Qualitative Information Obtained by NMR}

We now turn to an overview of possible applications of NMR spectroscopy related to microbiology. We find it convenient to classify those, somewhat arbitrarily, as qualitative or quantitative.

\section{Identification of Compounds}

It is often the case that metabolic pathways produce unknown end products and that NMR is called upon to help in identifying these compounds. This will be particularly true for recently discovered organisms, or for some branches of secondary metabolism. As this type of work is mostly done on supernatants or cell extracts, the investigator can bring to bear all the tools of high resolution, solution NMR. Chemical shifts, signal multiplicities and coupling constant are all useful; two-dimensional correlation maps greatly facilitate the process. The wealth of data available and the fact that NMR, contrary to other characterisation methods, is not specific of any one class 
of molecules are clearly advantageous. Some time ago, a novel molecule, 2,3-cyclo-pyro-diphosphoglycerate, was discovered on in vivo spectra and fully characterised; its role in gluconeogenesis was later established (12). Other metabolites, including osmolytes (13) and UDP amino sugars (14), have since been described. Kalic et al. (15) provide an instructive example (drawn from a study of a particular biofluid) of the power and limitations of this approach.

\section{Identification of Metabolic Pathways or Branches in Pathways}

Molecules involved in metabolism have a carbon backbone. It should therefore not be surprising to learn that the most powerful method to investigate a pathway consists in labelling carbon atoms in order to unravel their origin and fate. This can be done with high sensitivity with radioactive ${ }^{14} \mathrm{C}$ labelling, but it is very painstaking to obtain site-specific information inside a molecule. In contrast, ${ }^{13} \mathrm{C}$ NMR provides site information quite easily.

Analogous to the investigations reported in the previous paragraph, NMR spectroscopy can be used to identify new pathways or unknown branches. Given the present state of knowledge, discovering an entirely new pathway is an improbable event, but some steps are often clarified or confirmed by NMR. Again, it is mainly in the case of secondary metabolism, leading to complex molecules, that most applications will be found. We will only mention two extreme examples before referring readers to the references and the "Further Reading" section. Lelait and Grivet (16) used the labelling patterns of amino-acids (obtained after isolation and hydrolysis of proteins) to confirm the main metabolic pathways of acetogenic bacteria growing on ${ }^{13} \mathrm{C}$ labelled glucose or carbonate. Hajjaj et al. (17) grew the filamentous fungus Monascus ruber on ${ }^{13} \mathrm{C}_{1},{ }^{13} \mathrm{C}_{2}$ and ${ }^{13} \mathrm{C}_{1}{ }^{13} \mathrm{C}_{2}$ labelled acetate to delineate the complex biosynthesis of citrinin.

Hydrogen exchange with the solvent is readily characterised by NMR, provided the solvent atoms can be labelled in some way. Incubating a cell suspension in an ${ }^{1} \mathrm{H}_{2} \mathrm{O} /{ }^{2} \mathrm{H}_{2} \mathrm{O}$ mixture with a ${ }^{13} \mathrm{C}$ labelled substrate is a simple method; site-specific deuterium incorporation in the end products is revealed by the characteristic splitting of the carbon signals under deuterium coupling (18).

The previous paragraphs may have wrongly given the reader an impression that only labelling above the background abundance is useful. This is not the case, as the work of Pasternack et al. (19) testifies. These authors incubated Saccharomyces cerevisiae in the presence of $\left[1-{ }^{13} \mathrm{C}\right]$-glycine and formate in order to delineate onecarbon metabolism. NMR analysis of the metabolic products choline and adenine showed isotopic dilution, thus proving that formate can compete with glycine as a carbon donor.

NMR is also useful for investigations of ecosystems or complex bacterial populations. The presence of homoacetogens in the microflora of human feces was proven by Lajoie et al. (20) who detected doubly labelled acetate formed from $\mathrm{H}_{2}$ and ${ }^{13} \mathrm{CO}_{2}$.

\section{Metabolic Expression in Genetically Modified Organisms}

As the physiology and metabolism of naturally occurring micro-organisms become better known, genetically modified bacteria receive closer attention. The main question raised in connection with these organisms can be formulated as follows: are the implanted genes fully expressed or how are the desired functions operating? The work of Ansanay et al. (21) provides an illustration. These authors inserted the gene coding for the malolactic enzyme (from Lactococcus lactis) into the genomes of Saccharomyces cerevisiae and Schizosaccharomyces pombe. Biochemical analyses, ${ }^{13} \mathrm{C}$ labelling (from $\left[1-{ }^{13} \mathrm{C}\right]-$ glucose) and comparison of the two species showed that $S$. cerevisiae was indeed able to perform the malolactic fermentation, but with low yield due to a very inefficient malate transport system.

\section{Distinction of Inside and Outside of Cell: Number of Cell Compartments}

Several NMR parameters have been used to locate solutes either inside or outside of cells. The first method, historically, relies on the $\mathrm{pH}$ dependence of the chemical shift, specially that of phosphorylated compounds (see " $p H$ Measurements"). The appearance of several "inside" inorganic phosphate signals is a proof of the existence of several cellular compartments, each with a distinctive $\mathrm{pH}$. Another approach makes use of a non-toxic, nonpermeating shift and/or relaxation reagent. It is also possible to recognise atoms bound to the outside of the cell membrane.

A more recent technique is based on diffusion weighted spectra (22). The "inside" molecules have a rather low effective diffusion coefficient, while the "outside" ones diffuse faster; moreover, they flow with the perifusion medium. It is possible to completely suppress extracellular contributions to the proton spectrum.

The existence of distinct metabolic pools and the assignment of some intermediates to a specific pool can be established by NMR examination of labelling patterns. The availability of mutants in which specific enzymes are missing is advantageous (19).

\section{Channelling}

Eukaryotes harbour multi-enzyme complexes (so-called metabolons). A current hypothesis is that a substrate can move from one active site to another without being released in the cytosol. This motion is assumed to be stereospecific and to preclude label scrambling. Such a mechanism has been investigated in yeast (23).

\section{Quantitative Information}

Let us now point to some quantitative measurements derived from NMR observations. The number of such applications is continuously growing, so that we can't even hope to compile a complete list. 


\section{Cell Volume}

The determination of the volume of intracellular water is required for the calculation of any intracellular metabolite concentration. It is somewhat difficult to perform whatever the technique used, although the principle is simple. A nonpermeating inert solute is added to the culture medium and a spectroscopic signal is recorded in the absence and in the presence of the cells. The difference is proportional to the excluded volume, occupied by the cells. On the other hand, the total water volume, both in the presence and absence of cells, is determined from the signal intensities of a freely diffusable compound. The difficulty is that one is looking at small variations of large signals. A careful determination of the intracellular volume for a suspension of Enterococcus faecalis by proton NMR is reported in (24).

\section{Diffusion Coefficients}

It was mentioned earlier (see "Distinction of Inside and Outside Cell: Number of Cell Compartments") that spin echo NMR, in the presence of pulsed field gradients, was sensitive to the diffusion of solute molecules. A quantitative determination of diffusion coefficients, both inside and outside the cell is possible. A recent application concerns the structure of granules (flocs) and biofilms. In anaerobic fermenters, bacteria often aggregate in granules, which sometimes show a defined concentric arrangement of bacterial species. It is of great interest to determine the flow of substrates and products in and out of these structures. The same is true for biofilms, whether natural or artificial. First results on water mobility on these structures have been presented (25).

Diffusion measurements can also be used for internal cell volume determination. The technique is more involved than the methods described in the previous section, but more reliable. Using a detailed mathematical model for the restricted diffusion of water with exchange between two compartments, Pfeuffer et al. $(26,27)$ could determine volume changes in response to hypoosmotic and hyperosmotic conditions.

\section{Behaviour of Intracellular Macromolecules}

Since most enzymes operate inside the cell, one would be quite interested in establishing their properties in situ, as opposed to properties determined from cellular extracts, homogenous solutions or even crystals. As already mentioned, the possibility of observing well resolved NMR signals from intracellular macromolecules is remote. It has proved possible in some special cases. Some protons signals of haemoglobin are indeed observable in erythrocytes, because the molecule itself is quite concentrated, there is some segmental mobility and the resonances are shifted to an uncongested part of the spectrum by interaction with the paramagnetic iron atom. A approach which is rather powerful and more general is the biosynthetic labelling of the enzyme with a rare nucleus. This can be accomplished in good yield upon insertion of an inducible expression vector for the relevant gene in the microbe's genome. In the presence of the inductor, the enzyme is synthetised and, if a labelled amino-acid is present in the culture medium, it is incorporated. This technique has been very successfully applied to yeast and to mammalian cells (28). 5-fluorotryptophan was incorporated in various enzymes of the glycolytic pathway or of the Krebs cycle. Rotational correlation times and hence micro-viscosity coefficients could be derived from the observed line-widths.

\section{pH Measurements}

This staple of in vivo NMR uses either intrinsic probes (mainly phosphorylated compounds) or extrinsic reporter molecules. It is important to construct a calibration curve under conditions as similar as possible to those in the intracellular medium. Many synthetic indicators have been evaluated, including phosphonates (29) and fluorinated compounds (30). Fluorine derivatives have the advantages of a vanishing background and high $\mathrm{pH}$ sensitivity, but suffer from the drawback that they require a special spectrometer channel.

\section{Concentrations}

Non-invasive, real time, continuous determinations of concentrations represent the main uses of metabolic NMR. A few words of caution regarding experimental procedures have been offered in the section entitled "Sensitivity".

Relative concentrations are easily measured, but absolute concentrations are another matter; they can only be defined relative to some reference. The choice of a convenient reference merits some attention. The ideal compound gives a single sharp line well removed from any other signal of interest, does not interact with solutes or cells and is easily handled. For in vivo work, it is prudent to use an external reference, i.e. a sealed capillary containing the reference solution inside the main sample tube. An interesting substitute has been suggested (31). A dedicated electronic circuit (or even the decoupler) can be set to generate a signal similar to a free induction decay. This is picked up by the receiver coil, processed as a bona fide signal and produces a reference line, thus avoiding any contamination of the sample.

It must be pointed out that different concentrations are measured in biological NMR. Simplest to acquire and interpret are solute concentrations in the culture medium (or supernatant). One is mainly interested in substrates and end products, with perhaps a goal of establishing a carbon balance. Next come cell extracts, for which some biochemical questions must be considered: washing of cells and choice of extraction procedure. Disruption of cells (in a French press or by sonication), followed by protein (or nucleic acid) isolation and hydrolysis puts heavier emphasis on biochemical know-how but provides information on anabolic reactions and pathways. Finally, in vivo concentrations rely on free intracellular volume determinations.

To be significant, assays must refer to a known number of cells (or definite cell mass). It appears that the most common unit is the gram of dry cells. 


\section{Indirect Determination of Concentrations}

In contrast to the direct concentration measurements referred to in the previous section, it is also possible to assay NMR invisible compounds through the effect they have on visible solutes. An early example was the determination of intracellular $\mathrm{Mg}^{++}$through the variation of the chemical shift difference between the $\alpha$ and $\beta$ phosphorus resonances of ATP (32). Many ${ }^{19} \mathrm{~F}$ NMR indicators of $\mathrm{Mg}^{++}$and $\mathrm{Ca}^{++}$have been synthesised and evaluated (33). Oxygen concentrations can, within a limited range, be derived from spin-lattice $\left(T_{1}\right)$ relaxation times.

\section{Kinetics of Individual Reactions}

In vivo reaction rates can be measured using the technique of magnetisation transfer. Many versions of this experiment are known (34): steady-state saturation, transient saturation, two-dimensional exchange spectroscopy (EXSY). The principle of the method can be briefly stated. Consider a nucleus that can exist in two chemical environments (say $A$ and $B$ ) with distinct resonance frequencies $\left(f_{A}\right.$ and $\left.f_{B}\right)$ and can jump from one to the other (with rates $\mathrm{k}_{\mathrm{A}}$ from $\mathrm{A}$ and $\mathrm{k}_{\mathrm{B}}$ from $\mathrm{B}$ ). An example is the ${ }^{31} \mathrm{P}$ nucleus within a phosphate group taking part in the reaction:

$$
\mathrm{ADP}+\mathrm{PCr} \leftrightarrow \mathrm{ATP}+\mathrm{Cr}
$$

The magnetisation of the $\gamma$ phosphate of ATP evolves under two causes: spin-lattice relaxation and exchange with the $\mathrm{PCr}$ magnetisation. In the pulsed version we would look at the perturbation of (say) the ATP signal upon inversion of the $\mathrm{PCr}$ resonance (brought about by a weak selective pulse). In effect, we would be watching a competition between chemical exchange, which brings into the ATP site an inverted population of nuclei (negative signal) and spin-lattice relaxation which tends to restore a normal signal. The time scale of such an experiment is the relaxation time $T_{1}$ so that reactions much faster or much slower than the spin lattice relaxation cannot be investigated in this manner. The whole process is easily modelled by two first-order differential equations, the solutions of which can be fitted to the experimental results, allowing the determination of the rate constants for exchange. A recent example is given in (35) for the case of a genetically engineered yeast, while Roscher et al. (36) show how to apply the EXSY method.

\section{Transmembrane Fluxes}

The transport kinetics of ions, substrates or products across the cell membrane can be measured by NMR, provided inside and outside contributions can be recognised. Shift reagents can be used to create a difference in resonance frequencies; many such compounds are available for cation NMR, but interpretation of results can be difficult. The actual rate measurement techniques are quite diverse. If transport is slow, recording of successive spectra after injection of an external compound or resuspension of the cells in fresh medium may allow the monitoring of 'internal' and/or 'external' concentrations as functions of time. In the case of intermediate rate constants, the magnetisation transfer methods of the previous section are suitable. Here, the two exchanging sites are geometrically as well as spectroscopically different.

Because of its high sensitivity and ubiquitous occurrence, sodium has been the subject of many investigations. It has proved, however, rather difficult to quantify the NMR visibility of internal sodium, which has been variously reported to be in the range $30-60 \%(37,38)$. ${ }^{23} \mathrm{Na}$ is a spin $3 / 2$ nucleus. When the ion moves slowly, or is bound to a partially oriented macromolecular structure (such as the cyto-skeleton), double and triple quantum transitions become observable and provide a possible technique to assay internal sodium. A complete theoretical treatment is available (39).

Potassium is difficult to observe and at least two substitutes have been proposed: rubidium and caesium. ${ }^{133} \mathrm{Cs}^{+}$would seem to offer two advantages (40). Its quadrupole moment is 200 times lower than that of sodium, promising rather sharp lines, and its chemical shift is so highly sensitive to the environment that the internal and external ions have spontaneously resolved resonances.

The transport of organic solutes can be examined in much the same way, but it is usually slower than that of ions. The case of ethanol efflux from Zymonas mobilis is an exception. It is fast enough for magnetisation transfer methods to be applied (41).

\section{Metabolic Flux}

Metabolic fluxes, or ratio of fluxes at branch points, are the main quantitative data sought by workers interested in metabolism. They are the equivalent of the $\mathrm{V}_{\max }$ and $\mathrm{K}_{\mathrm{m}}$ of enzymology. They cannot be determined from NMR measurements alone when using a single label. This fact was well known of the practitioners of radioactive labelling who coined the term 'specific activity' (counts per minute per gram of product). It is sometimes masked in NMR; because of its low sensitivity, this analytical technique operates not with tracer amounts but with labelled compounds which form a notable proportion of the substrate. The difficulty can be traced to the fact that isotopic equilibrium (or flux) is different from substrate equilibrium (or flux). In order to stress the point, we submit to the reader a somewhat far-fetched analogy. Suppose that we wish to determine the flow rate of a mountain stream. This is rather laborious to do; we would have to measure the (cold) water speed at many points of the stream cross-section and sum all contributions. Instead, we may decide to dump a known number of fishes into the water and count how many of them pass under a bridge downstream. This method is the analogue of the simple NMR approach mentioned above.

The enrichment of a product $P$, that is the ratio [labelled $\mathrm{P}] /[$ total $\mathrm{P}]$, must be known before any conclusion on the corresponding flux can be drawn. The amount of $P$ in a culture can be, in principle, determined with any analytical technique. For instance, Dominguez et al. (42) combined acidic and basic extraction procedures, HPLC and fluorescence assays with ${ }^{13} \mathrm{C}$ NMR analysis of labelling patterns to determine carbon fluxes in the central metabolism of Corynebacterium glutamicum. 
Combining results derived from several techniques and several samples should be considered with some caution. Several investigators have proposed methods using only NMR. One approach (43) uses proton NMR and ${ }^{13} \mathrm{C}$ labelling; on the proton spectrum, both unlabelled and labelled product can be observed, provided the $\mathrm{C}-\mathrm{H}$ coupling constant is large enough, as is the case for $\mathrm{CH}_{n}$ groups. Wendisch et al. (44) have developed a frequency selective spin echo difference technique which remains useful for non-protonated carbons. Any magnetically active nucleus coupled to carbon could be used; Lutz et al. (45) have taken advantage of ${ }^{31} \mathrm{P}-{ }^{13} \mathrm{C}$ couplings to determine the specific enrichment of phosphorylated metabolites.

The most powerful method is probably the analysis of amino acid multiplet patterns arising when micro-organisms are fed with uniformly labelled glucose, as first described by Gagnaire and Taravel (46) and perfected by Szyperski et al. One is sometimes interested in the global turnover or renewal rate of a whole family of molecules, for instance amino acids. Roberts et al. (47) used ${ }^{15} \mathrm{~N}$ NMR to measure the free amino-acid turnover rate in methanogens.

Up to now, we have been mainly concerned with pure species; however, some quantitative work has been done on mixed cultures and complete ecosystems. Wolin et al. (48) examined the colonisation of the digestive tracts of infants by Bifidobacteria. These micro-organisms use a unique pathway of hexose catabolism to produce acetate and lactate. One third of the acetate molecules are derived entirely from the $\mathrm{C}_{3}$ carbon. Fermentation of $\left[3^{-13} \mathrm{C}\right]-$ glucose thus yields doubly labelled acetate, with a characteristic spectrum. It was shown that $70 \%$ of the acetate produced by a bacterial suspension was due to Bifidobacteria.

\section{Are Isotopic Substitutions Innocuous?}

After reading the previous sections, the reader has no doubt noticed that isotopic labelling is one of the main tools of metabolic NMR. He or she may well wonder whether substituting a nucleus by a lighter or heavier isotope has any effect on the biochemical reactions being studied. A short answer is no, except possibly for the hydrogen isotopes. Isotope effects on chemical and biochemical reactions have been extensively studied during the last fifty years. Chemical equilibria are slightly displaced upon isotopic substitution, but the effect is too small to have observable consequences on living systems.

Of greater import are the modifications of rate constants. Hydrogen exchanges can be slowed down by a factor of ten when protium is replaced by deuterium. This is probably the reason why eukaryotes and higher organisms cannot live on heavy water. Kinetic isotope effects are much smaller for heavier nuclei. Organic reactions rates can be reduced by a few percent when ${ }^{12} \mathrm{C}$ is replaced by ${ }^{13} \mathrm{C}$. The resulting small concentration changes can be monitored by mass spectrometry and have been used as probes of reaction mechanisms (49).

Metabolic pathways operating in micro-organisms comprise many enzymatic reactions; a given metabolite is often synthesised by several routes. The end result is that apparent isotope effects become small (a few per mil, not detectable by NMR) and difficult to interpret, except when they can be related to a single rate limiting step. The ${ }^{1} \mathrm{H} /{ }^{2} \mathrm{H}$ couple is again an exception, with variations in relative abundance of several percent. We refer the reader to the literature (50) for the many interesting applications of sitespecific natural isotope fractionation.

\section{Probable and/or Desirable Developments}

We will end by listing some technical developments that should in the near future make NMR more productive or easier to use for the microbiologist. This list is not speculative, as the technology already exists for these improvements.

\section{High Field, Wide Bore Magnets}

Higher fields will mean more sensitivity, allowing observation of low $\gamma$ nuclei and/or the use of lower enrichment for rare nuclei. As structural biochemists reach for ever increasing fields, one may hope that many $11.7 \mathrm{~T}$ (500 MHz for protons) spectrometers will be converted to metabolic work. A similar trend is seen in biofluid analysis, although here the driving force is the necessity of improving the resolution of proton spectra.

\section{Microprobes}

Manufacturers as well as several research groups (51) are developing probes for very small volumes (1-100 microlitres). They could be used in conjunction with very small scale cultures.

\section{High Pressure Probes and NMR of Gases}

It is now possible to do high resolution NMR under pressures of $500 \mathrm{MPa}(5000 \mathrm{~atm})(52)$. It is conceivable that gas consumption and production $\left(\mathrm{H}_{2}, \mathrm{CH}_{4}\right)$ by methanogens or acetogens and interspecific hydrogen transfer could be studied in vivo with these specialised probes.

Instead of increasing the effective concentration of a gas, one could think of increasing the apparent magnetic moment (or the $\gamma$ factor) of the nuclei. This seemingly ludicrous goal can be reached in two cases: ${ }^{3} \mathrm{He}$ and ${ }^{129} \mathrm{Xe}$, using optical pumping techniques (53). Although of doubtful biochemical significance in themselves, these gases could serve to explore the geometric structure of microbial aggregates (flocs, granules), much as is now being developed for lung and vascular imaging.

\section{Spectroscopic Imaging}

Magnetic resonance imaging, or MRI, is a well known noninvasive investigative technique, useful in material science and in medicine. It is usually implemented with large, horizontal bore magnets. A micro-scale version of MRI uses a vertical bore magnet. The ultimate resolution is estimated as 10 micrometers, although current images show details at about 50 micrometers. This is sufficient to investigate heterogeneous samples, such as granules, biofilms or bioreactors as mentionned earlier (see "Diffusion Coefficients"). Using special pulse sequences, it is possible 
to perform spectroscopic imaging, wherein a threedimensional concentration map of several abundant metabolites is constructed for an organ such as the brain. The spatial resolution is of the order of half a centimetre. The challenge consists in combining a high spatial resolution and chemical sift information.

\section{Data Banks and Data Processing}

To this author's knowledge, no NMR data bank useful for metabolism exits at the present time. The many compilations of chemical shifts that do exist mainly concern organic chemistry: spectra were recorded in organic solvents, for neutral molecules. We believe that it would be useful to collect chemical shifts, coupling constants, pK's of molecules frequently encountered in metabolic work, along with an accurate description of conditions: $\mathrm{pH}$, ionic strength, concentration, temperature.

The use of NMR spectroscopy for research in physiology or metabolism involves the recording and analysing of a great number of spectra and there is a need for the automation of the whole process. Software for the automatic treatment and analysis of spectra is available but, in the author's opinion, no single program can yet handle the variety of spectra and practical problems met when performing in vivo NMR.

\section{Conclusion}

We hope that this overview of possible NMR applications in microbiology will encourage readers to consider the use of NMR whenever a problem arises in their own research.

\section{References}

1. Eakin, R .J, Morgan, L.O., Gregg, C.T. and Matwyoff, N.A. 1972 Carbon-13 nuclear magnetic resonance spectroscopy of living cells and their metabolism of a specifically labeled ${ }^{13} \mathrm{C}$ substrate. FEBS Lett. 28: 259-264.

2. Guéron, M., Plateau, P. and Décorps, M. 1991. Solvent signal suppression in NMR. Progr. NMR Spectr. 23: 135-209.

3. Gillet, S. and Delpuech, J.-J. 1980. Optimum conditions for nondestructive quantitative analysis by carbon-13 NMR. J. Magn. Res. 38: 433-445.

4. Maniara, G., Rajamoorthi, K., Rajan, S. and Stockton, G.W. 1998. Method performance and validation for quantitative analysis by ${ }^{1} \mathrm{H}$ and ${ }^{31} \mathrm{P}$ NMR analysis. Application to analytical standards and agricultural chemicals. Anal. Chem. 70: 4921-4928.

5. Freeman, R. and Kupce, E. 1997. Decoupling: Theory and Practice: I. Current methods and recent concepts. NMR Biomed. 10: 372-380.

6. Freeman, D.M. and Hurd, R. 1997. Decoupling: theory and Practice: II. State of the art: in vivo applications of decoupling. NMR Biomed. 10: 381-393.

7. Majumdar, A. and Sonawat, H.M. 1998. A two-dimensional ${ }^{1} \mathrm{H}$ detected ${ }^{13} \mathrm{C}$ NMR investigation of pyruvate metabolism in Halobacterium salinarum. J. Biochem. 123: 115-119.

8. Grivet, J.-P. 1996. Accuracy and precision of intensity determinations in quantitative NMR. In: Signal Treatment and Signal Analysis in NMR. D.N. Rutledge ed. Elsevier, Amsterdam, Netherlands. p 306-329.

9. Hutton, W.C., Likos, J.J., Gard, J.K. and Garbo, J.R. 1998. Triple resonance isotope-edited (TRIED): A powerful new NMR technique for studying metabolism. J. Label. Comp. 41: 87-95.

10. Navon, G., Kushnir, T., Askenasy, N. and Kaplan, O. 1992. Twodimensional ${ }^{31} \mathrm{P}-{ }^{1} \mathrm{H}$ correlation spectroscopy in intact organs and their extracts. NMR, Basic Principles and Progress. 27: 237-255.

11. Dalvit, C. and Bohlen, J.-M. 1997. Analysis of biofluids and chemical mixtures in non deuterated solvents with ${ }^{1} \mathrm{H}$ diffusion-weighted PFG phase-sensitive double-quantum NMR spectroscopy. NMR Biomed. 10: 285-291.

12. Gorkovenko A. and Roberts, M.F. 1993. Cyclic-2,3-diphosphoglycerate as a component of a new branch in gluconeogenesis in Methanobacterium thermoautrophicum $\Delta \mathrm{H}$. J. Bact. 175: 4087-4095. 13. Ciulla, R.A., Diaz, M.R., Taylor, B.F. and Roberts, M.F. 1997. Organic osmolytes in anaerobic bacteria from Mono Lake, an alkaline, moderately saline environment. Appl. Environ. Microbiol. 63: 220-226.

14. Ramkrishnan, V., Teng, Q. and Adams, M.W. 1997. Characterisation of UDP amino sugars as major phosphocompounds in the hyperthermophilic archeon Pyrococcus furiosus. J. Bacteriol. 179: 1505-1512.

15. Kalic, M., Kamp, G. and Lauterwein, J. 1997. Nuclear magnetic resonance studies of boar seminal plasma. Problems encountered in the identification of small molecules: hypotaurine and carnitine. NMR Biomed. 10: 341-347.

16. Lelait, M. and Grivet, J.-P. 1996. Carbon metabolism in Eubacterium limosum: a ${ }^{13} \mathrm{C}$ NMR study. Anaerobe. 2: 181-209.

17. Hajjaj, H., Klaébé, A., Goma, G., Blanc, P.J. and François, J. 1999. Biosynthetic pathway of citrinin in the filamentous fungus Monascus ruber as revealed by ${ }^{13} \mathrm{C}$ nuclear magnetic resonance. Appl. Environ. Microbiol. 65: 311-314.

18. Frydman, B., de los Santos, C., Cannata, J.J.B. and Cazzulo, J.J., 1990. Carbon-13 nuclear magnetic resonance analysis of $1-{ }^{13} \mathrm{C}$ glucose metabolism in Trypanosoma cruzi. Eur. J. Biochem. 192: 363368.

19. Pasternack, L.B., Littlepage, L.E., Laude, D.A. Jr. and Appling, D.R. 1996. ${ }^{13} \mathrm{C}$ NMR analysis of the use of alternative donors to the tetrahydrofolate-dependant one-carbon pools in Saccharomyces cerevisiae. Arch. Biochem. Biophys. 326: 158-165.

20. Lajoie, S.F., Bank, S., Miller, T.L. and Wolin, M.J. 1988. Acetate production from hydrogen and $\left[{ }^{13} \mathrm{C}\right]$ carbon dioxide by the microflora of human feces. Appl. Environ. Microbiol. 54: 2723-2727.

21. Ansanay, V., Dequin, S. Camarasa, C., Scheaffer, V., Grivet, J.-P., Blondin, B., Salmon, J.-M. and Barre P. 1996. Malolactic fermentation by engineered Saccharomyces cerevisiae as compared with engineered Schizosaccharomyces pombe. Yeast. 12: 215-225.

22. van Zijl, P.C., Moonen, C.T.W., Faustino, P., Pekar, J., Kaplan, O. and Cohen, J.S. 1991. Complete separation of intracellular and extracellular information in NMR spectra of perfused cells by diffusionweighted spectroscopy. Proc. Nat. Acad. Sci. 88: 3228-3232.

23. Sumegi, B., Sherry, A.D., Malloy, C.R. and Srere, P.A. 1993. Evidence for orientation-conserved transfer in the TCA cycle in Saccharomyces cerevisiae: ${ }^{13} \mathrm{C}$ NMR studies. Biochem. 32: 12725-12729.

24. Hockings, P.D. and Rogers, P.J. 1994. ${ }^{1} \mathrm{H}$ NMR determination of intracellular volume in cell suspensions. Arch. Biochem. Biophys. 311 383-388.

25. Beuling, E.E., van Dusschoten, D., Lens, P., van den Heuvel, J.C., van Has, H. and Ottengraf, S.P.P. 1998. Characterization of the diffusive properties of biofilms using pulsed field gradient nuclear magnetic resonance. Biotechnol. Bioeng. 60: 283-291.

26. Pfeuffer, J., Flögel, U. and Leibfritz, D. 1998. Monitoring of cell volume and water exchange time in perfused cells by diffusion-weighted ${ }^{1} \mathrm{H}$ NMR spectroscopy. NMR Biomed. 11: 11-18.

27. Pfeuffer, J., Flögel, U., Dreher, W. and Leibfritz, D. 1998. Restricted diffusion and exchange of intracellular water: theoretical modelling and diffusion time dependence of ${ }^{1} \mathrm{H}$ NMR measurements on perfused glial cells. NMR Biomed. 11: 19-31.

28. Williams, S.P., Haggie, P.M. and Brindle, K.M. 1997. ${ }^{19} \mathrm{~F}$ NMR measurements of the rotational mobility of proteins in vivo. Biophys. J. $72:$ 490-498.

29. Bruynseels, K., Gillis, N., van Heck, P. and Vanstapel, F., 1997. Phosphonates as ${ }^{31} \mathrm{P}-\mathrm{NMR}$ markers of extra- and intracellular space and $\mathrm{pH}$ in perfused rat liver. NMR Biomed. 10: 263-270.

30. Mehta, V.D., Kulkarni, P.V., Mason, R.P. Constantinescu, A., Aravind, S., Goomer, N. and Antich, P. P. 1994. 6-fluoropyridoxol: a novel probe of cellular pH using ${ }^{19} \mathrm{~F}$ NMR spectroscopy. FEBS Lett. 349: 234-238.

31. Barantin, L., Le Pape, A. and Akoka, S. 1997. A new method for absolute quantitation of MRS metabolites. Magn. Res. Med. 38: 179182.

32. Gupta, R.K. and Gupta, P. 1984. NMR studies of intracellular metal ions in intact cells and tissues. Ann. Rev. Biophys. Bioeng. 13:221246.

33. Levy, L.A., Murphy, E., Raju, B. and London, R.E. 1988. Measurement of cytosolic free magnesium ion concentration by ${ }^{19} \mathrm{~F}$ NMR. Biochem. 27: 4041-4048.

34. Rudin, M. and Sauter, A. 1992. Measurement of reaction rates in vivo using magnetisation transfer techniques. NMR, Basic Principles and Progress. 27: 259-293.

35. Sheldon, J.G., Williams, S.P., Fulton, A.M. and Brindle, K.M. 1996 ${ }_{31}$ P NMR magnetisation transfer study of the control of ATP turnover in Saccharomyces cerevisiae. Proc. Nat. Acad. Sci. 93: 6399-6404. 
36. Roscher, A., Emsley, L., Raymond, P. and Roby, C. 1998. Unidirectional steady state rates of central metabolism enzymes measured simultaneously in a plant tissue. J. Biol. Chem. 273: 25-53-25061.

37. Nagata, S., Adachi, K., Shirai, K. and Sano, H. $1995 .{ }^{23} \mathrm{Na}$ NMR spectroscopy of free $\mathrm{Na}^{+}$in the halotolerant bacterium Brevibacterium sp. and Escherichia coli. Microbiol. 140: 729-736.

38. Rabaste, F., Dauphin, G., Geminet, G., Guyot, J. and Delort, A.-M., 1991. Phosphate dependant sodium transport in $S$. feacalis investigated by ${ }^{23} \mathrm{Na}$ and ${ }^{31} \mathrm{P}$ NMR. Biochem. Biophys. Res. Comm. 181: 74-79.

39. Rooney, W.D. and Springer, C.S. Jr. 1991. A comprehensive approach to the analysis and interpretation of the resonances of spins $3 / 2$ from living systems. NMR Biomed. 4: 209-226. The molecular environment of intracellular sodium: ${ }^{23} \mathrm{Na}$ NMR relaxation. NMR Biomed. 4: 227245.

40. Schornack, P.A., Song, S.-K., Ling, C.S., Hotchkiss, R. and Ackerman, J.J.H. 1997. Quantification of ion transport in perfused rat heart: ${ }^{133} \mathrm{Cs}^{+}$ as an NMR active $\mathrm{K}^{+}$analog. Am. J. Physiol. 272: C1618-C1634.

41. Schobert, S.M., Chapman, B.E., Kuchel, P.W., Wittig, R.M. Grotendorst, J., Jansen, P. and de Graaf, A.A. 1996. Ethanol transport in Zymonas mobilis measured by using in vivo nuclear magnetic resonance spin transfer. J. Bacteriol. 178: 1756-1761.

42. Dominguez, H., Rollin, C., Guyon-Varch, A., Guerquin-Kern, J.-L. Cocaign-Bousquet, L. and Lindley, N. 1998. Carbon-flux distribution in the central metabolic pathways of Corynebacterium glutamicum during growth on fructose. Eur. J. Biochem. 254: 96-102.

43. Szyperski, T. 1995. Biosynthetically directed fractional ${ }^{13} \mathrm{C}$-labeling of proteinogenic amino acids. An efficient analytical tool to investigate intermediary metabolism. Eur. J. Biochem. 232: 433-448.

44. Wendisch, V.F., de Graaf, A.A. and Sahm, H. 1997. Accurate determination of ${ }^{13} \mathrm{C}$ enrichments in non-protonated carbon atoms of isotopically enriched amino acids by ${ }^{1} \mathrm{H}$ nuclear magnetic resonance. Anal. Biochem. 245: 196-202.

45. Lutz, N., Yahi, N., Fantini, J. and Cozzone, P.J. 1996. A new method for the determination of specific ${ }^{13} \mathrm{C}$ enrichment in phosphorylated [1 ${ }^{13} \mathrm{C}$ lglucose metabolites. ${ }^{13} \mathrm{C}$-coupled, ${ }^{1} \mathrm{H}$-decoupled ${ }^{31} \mathrm{P}$-NMR spectroscopy of tissue perchloric acid extracts. Eur. J. Biochem. 238: 470-475.

46. Gagnaire, D.Y. and Taravel, F.R. 1980. Biosynthèse de cellulose bactérienne à partir de $\mathrm{D}$-glucose uniformément enrichi en ${ }^{13} \mathrm{C}$. Eur. J. Biochem. 103: 133-143.

47. Roberts, M.F., Choi, B.-S., Robertson, D.E. and Lesage, S. 1990 Free amino acid turnover in methanogens measured by ${ }^{15} \mathrm{~N}$ NMR spectroscopy. J. Biol. Chem. 265: 18207-18212.

48. Wolin, M.J., Zhang, Y., Bank, S., Yerry, S. and Miller, T.L. 1998. NMR detection of ${ }^{13} \mathrm{CH}_{3}{ }^{13} \mathrm{COOH}$ from $3^{-13} \mathrm{C}$-glucose: a signature for Bifidobacterium fermentation in the intestinal tract. J. Nutr. 128: 91 96.

49. O'Leary, M.H. 1980. Determination of heavy atom isotope effects on enzyme-catalysed reactions. Meth. Enzymol. 64B: 83-104.

50. Martin, M.L. and Martin G.J. 1990. Deuterium NMR in the study of site-specific natural isotope fractionation (SNIF-NMR). NMR Basic Principles and Progress, 23:1-61.

51. Subramanian, R. and Webb, A.G. 1998. Design of solenoidal microcoils for high-resolution ${ }^{13} \mathrm{C}$ NMR spectroscopy. Anal. Chem. 70: 2454-2458

52. Jonas, J., Ballard, L. and Nash, D. 1998. High-resolution, highpressure NMR studies of proteins. Biophys. J. 75: 445-452.

53. Chen, X.J., Chawla, M.S., Hedlund, L.W. Moller, H.E., MacFall, J.R and Johnson, G.A. 1998. Magnetic resonance microimaging of lung airways with hyperpolarised ${ }^{3} \mathrm{He}$. Magn. Reson. Med. 39: 79-84.

\section{Further Reading}

General

NMR in Microbiology: Theory and Applications. J.N. Barbotin and J.C. Portais eds. Horizon Scientific Press, Wymondham, UK, 2000.

\section{Osmolytes}

Gouggi, K., Bernard, T. and Blanco, C. 2000. Osmoprotection by pipecolic acid in Sinorhizobium meliloti: specific effects of $D$ and $L$ isomers. Appl. Environ. Microbiol. 65: 2358-2354.

\section{New Pathways}

Pitson, S.M., Mendez, G.L., Srinivasan, S. and Hazell, S.L. 1999. The tricarboxylic acid cycle of Helicobacter pylori. Eur. J. Biochem. 260: 258267.

Rager, M.N., Binet, M.R. and Bouvet, O.M. 1999. ${ }^{31} \mathrm{P}$ and ${ }^{13} \mathrm{C}$ nuclear magnetic resonance studies of metabolic pathways in Pasteurella multicocida: characterization of a new mannitol-producing metabolic pathway. Eur. J. Biochem. 263: 695-701.

\section{Genetically Modified Organisms}

Marx, A., Eikmanns, B.J., Sahm, H., de Graaf, A.A. and Eggeling, L. 1999 Response of the central metabolism in Corynebacterium glutamicum to the use of an $\mathrm{NADH}$-dependant glutamate dehydrogenase . Metabolic Engineering 1:35-48.

Ramos, A., Boelas, I.C., de Vos, W.M. and Santos, H. 2001. Relationship between glycolysis and exopolysaccharide biosynthesis in Lactotcocus lactis. Appl. Environ. Microbiol. 67: 33-41.

Eisenreich, W. and Bacher, A. Elucidation of biosynthetic pathways by retrodictive/predictive comparison of isotopomer patterns determined by NMR spectroscopy. In Genetic Engineering, Principles and Methods, vol. 22, J.K. Setlow ed. Kluwer Academic, Dordrecht, Netherlands.

\section{Diffusion Coefficients}

Schobert, S.M., Bar, N.K., Kramer R. and Karger, J. 2000. Pulsed highfield gradient in vivo NMR spectroscopy to measure diffusional water permeability in Corynebacterium glutamicum. Anal. Biochem. 279: 100105.

Isotopic Dilution:

Bibollet, X., Bosc, N., Matulova, M., Delort, A.M., Gaudet, G. and Forano E. 2000. ${ }^{13} \mathrm{C}$ and ${ }^{1} \mathrm{H}$ NMR study of cellulose metabolism in Fibrobacter succinogenes S85. J. Biotechnol. 77: 37-47.

\section{Metabolic Flux}

Tesch, M., de Graaf, A.A. and Sahm, H. 1999. In vivo fluxes in the ammonium assimilatory pathways in Corynebacterium glutamicum studied by ${ }^{15} \mathrm{~N}$ nuclear magnetic resonance. Appl. Environ. Microbiol. 65: 1099-1109.

Deborde, C. and Boyaval, P. 2000. Interactions between pyruvate and lactate metabolism in Propionibacterium freudenreichii subsp. Shermani: In vivo ${ }^{13} \mathrm{C}$ nuclear magnetic resonance studies. Appl. Environ. Microbiol. 66 : 2012-2020.

Schmidt, K., Nielsen, J. and Villadsen, J. 1999. Quantitative analysis of metabolic fluxes in Escherichia coli, using two-dimensional NMR spectroscopy and complete isotopomer models. J. Biotechnol. 71: 175189.

\section{Metabolic Flux in an Ecosystem}

Wolin, M.J., Miller, T.L., Yerry, S., Zhang, Y., Bank, S. and Weaver, G.A 1999. Changes of fermentation pathways of fecal microbial communities associated with a drug treatment that increases dietatary starch in the human colon. Appl. Environ. Microbiol. 65: 2807-2812.

\section{Isotope Effects}

Hochuli, M., Szyperski, T. and Wüthrich, K. 2000. Deuterium isotope effects on the central carbon metabolism of Escherichia coli cells growing on a $\mathrm{D}_{2} \mathrm{O}$-containing minimal medium. J. Biomol. NMR 17:33-42.

\section{Microprobe}

Gilbert, M., Brisson, J.R., Karwaski, M.F., Michniewicz, J., Cunningham A.M., Wu, Y., Young, N.M. and Wakarchuk, W.W. 2000. Biosynthesis of ganglioside mimics in Campylobacter jejuni $\mathrm{OH}$ 4384. Identification of glycosyltransferase genes, enzymatic synthesis of model compounds, and characterization of nanomole amounts by $600 \mathrm{MHz}{ }^{1} \mathrm{H}$ and ${ }^{13} \mathrm{C}$ NMR analysis. J. Biol. Chem. 275: 3896-3906.

\section{Coupled Chromatography-NMR Analysis}

Abel, C.B., Lindon, J.C., Noble, D., Rudd, B.A., Sidebottom, P.J., Nicholson, J.K. 1999. Characterization of metabolites in intact Streptomyces citicolo culture supernatants using high resolution nuclear magnetic resonance and directly coupled high pressure chromatography-nuclear magnetic resonance spectroscopy. Anal. Biochem. 270: 220-230. 


\section{Further Reading}

Caister Academic Press is a leading academic publisher of advanced texts in microbiology, molecular biology and medical research. Full details of all our publications at caister.com

- MALDI-TOF Mass Spectrometry in Microbiology Edited by: M Kostrzewa, S Schubert (2016) www.caister.com/malditof

- Aspergillus and Penicillium in the Post-genomic Era Edited by: RP Vries, IB Gelber, MR Andersen (2016) www.caister.com/aspergillus2

- The Bacteriocins: Current Knowledge and Future Prospects Edited by: RL Dorit, SM Roy, MA Riley (2016)

www.caister.com/bacteriocins

- Omics in Plant Disease Resistance Edited by: V Bhadauria (2016) www.caister.com/opd

- Acidophiles: Life in Extremely Acidic Environments Edited by: R Quatrini, DB Johnson (2016) www.caister.com/acidophiles

- Climate Change and Microbial Ecology: Current Research and Future Trend

Edited by: J Marxsen (2016)

www.caister.com/climate

- Biofilms in Bioremediation: Current Research and Emerging Technologies

Edited by: G Lear (2016)

www.caister.com/biorem

- Microalgae: Current Research and Applications Edited by: MN Tsaloglou (2016) www.caister.com/microalgae

- Gas Plasma Sterilization in Microbiology: Theory, Applications, Pitfalls and New Perspectives Edited by: H Shintani, A Sakudo (2016) www.caister.com/gasplasma

- Virus Evolution: Current Research and Future Directions Edited by: SC Weaver, M Denison, M Roossinck, et al. (2016) www.caister.com/virusevol

- Arboviruses: Molecular Biology, Evolution and Control Edited by: N Vasilakis, DJ Gubler (2016) www.caister.com/arbo

- Shigella: Molecular and Cellular Biology Edited by: WD Picking, WL Picking (2016) www.caister.com/shigella

-Aquatic Biofilms: Ecology, Water Quality and Wastewater Treatment

Edited by: AM Romaní, H Guasch, MD Balaguer (2016)

www.caister.com/aquaticbiofilms

- Alphaviruses: Current Biology

Edited by: S Mahalingam, L Herrero, B Herring (2016)

www.caister.com/alpha

- Thermophilic Microorganisms

Edited by: F Li (2015)

www.caister.com/thermophile
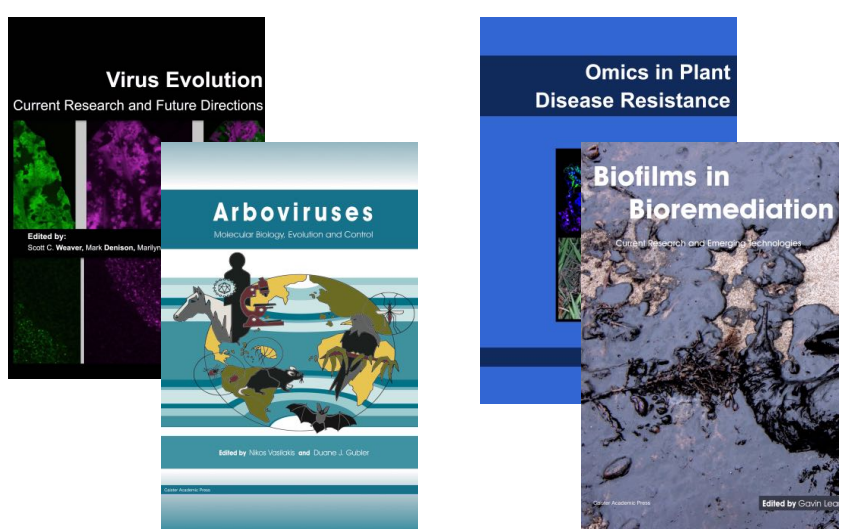
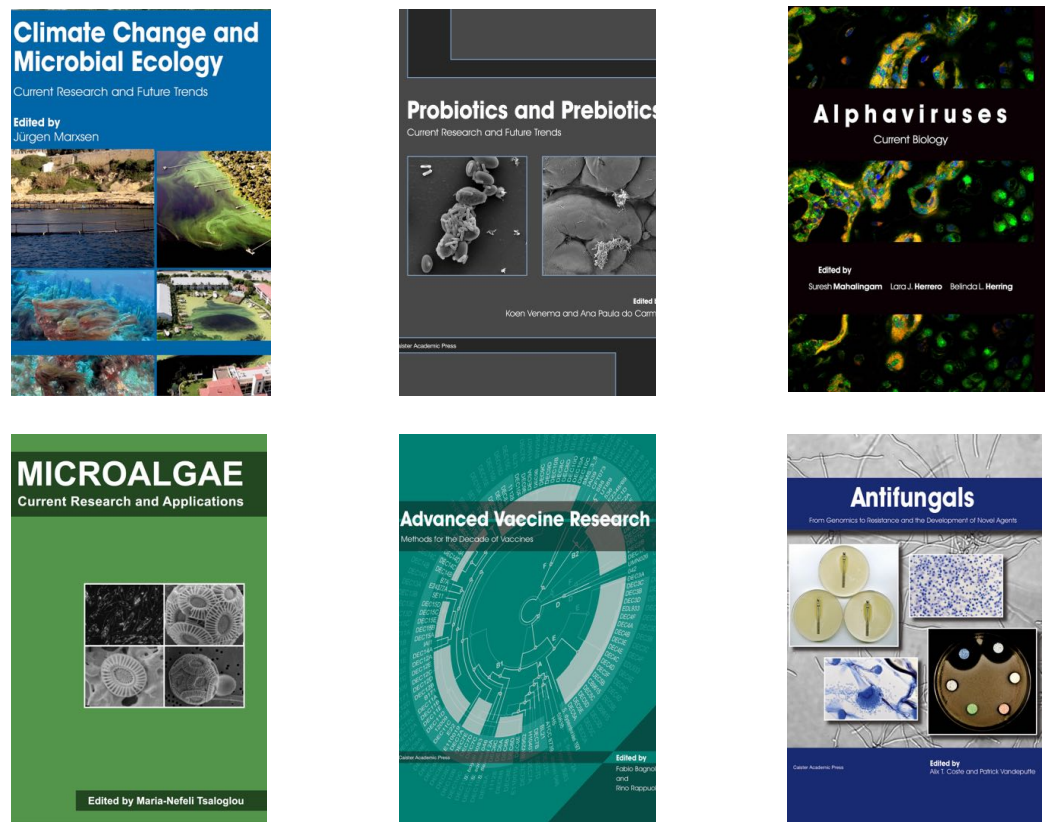

- Flow Cytometry in Microbiology: Technology and Applications Edited by: MG Wilkinson (2015) www.caister.com/flow

- Probiotics and Prebiotics: Current Research and Future Trends Edited by: K Venema, AP Carmo (2015) www.caister.com/probiotics

- Epigenetics: Current Research and Emerging Trends Edited by: BP Chadwick (2015) www.caister.com/epigenetics2015

- Corynebacterium glutamicum: From Systems Biology to Biotechnological Applications

Edited by: A Burkovski (2015)

www.caister.com/cory2

- Advanced Vaccine Research Methods for the Decade of Vaccines

Edited by: F Bagnoli, R Rappuoli (2015)

www.caister.com/vaccines

- Antifungals: From Genomics to Resistance and the Development of Novel Agents

Edited by: AT Coste, P Vandeputte (2015)

www.caister.com/antifungals

- Bacteria-Plant Interactions: Advanced Research and Future Trends Edited by: J Murillo, BA Vinatzer, RW Jackson, et al. (2015) www.caister.com/bacteria-plant

\section{- Aeromonas}

Edited by: J Graf (2015)

www.caister.com/aeromonas

- Antibiotics: Current Innovations and Future Trends

Edited by: S Sánchez, AL Demain (2015)

www.caister.com/antibiotics

- Leishmania: Current Biology and Contro Edited by: S Adak, R Datta (2015) www.caister.com/leish2

- Acanthamoeba: Biology and Pathogenesis (2nd edition) Author: NA Khan (2015)

www.caister.com/acanthamoeba2

- Microarrays: Current Technology, Innovations and Applications Edited by: Z He (2014)

www.caister.com/microarrays2

- Metagenomics of the Microbial Nitrogen Cycle: Theory, Methods and Applications

Edited by: D Marco (2014)

www.caister.com/n2 